\title{
Shifted termination assay (STA) fragment analysis to detect BRAF V600 mutations in papillary thyroid carcinomas
}

So Young Kang ${ }^{1,5}$, Soomin Ahn ${ }^{1}$, Sun-Mi Lee ${ }^{2}$, Ji Yun Jeong ${ }^{3}$, Ji-Youn Sung ${ }^{4}$, Young Lyun Oh ${ }^{1 *}$ and Kyoung-Mee $\mathrm{Kim}^{1 *}$

\begin{abstract}
Background: BRAF mutation is an important diagnostic and prognostic marker in patients with papillary thyroid carcinoma (PTC). To be applicable in clinical laboratories with limited equipment, diverse testing methods are required to detect BRAF mutation.

Methods: A shifted termination assay (STA) fragment analysis was used to detect common V600 BRAF mutations in 159 PTCs with DNAs extracted from formalin-fixed paraffin-embedded tumor tissue. The results of STA fragment analysis were compared to those of direct sequencing. Serial dilutions of BRAF mutant cell line (SNU-790) were used to calculate limit of detection (LOD).

Results: BRAF mutations were detected in 119 (74.8\%) PTCs by STA fragment analysis. In direct sequencing, BRAF mutations were observed in 118 (74.2\%) cases. The results of STA fragment analysis had high correlation with those of direct sequencing $(p<0.00001, k=0.98)$. The LOD of STA fragment analysis and direct sequencing was $6 \%$ and 12.5\%, respectively. In PTCs with pT3/T4 stages, BRAF mutation was observed in $83.8 \%$ of cases. In pT1/T2 carcinomas, BRAF mutation was detected in $65.9 \%$ and this difference was statistically significant $(p=0.007)$. Moreover, BRAF mutation was more frequent in PTCs with extrathyroidal invasion than tumors without extrathyroidal invasion $(84.7 \%$ versus $62.2 \%, p=0.001)$. To prepare and run the reactions, direct sequencing required 450 minutes while STA fragment analysis needed 290 minutes.
\end{abstract}

Conclusions: STA fragment analysis is a simple and sensitive method to detect BRAF V600 mutations in formalinfixed paraffin-embedded clinical samples.

Virtual Slides: The virtual slide(s) for this article can be found here: http://www.diagnosticpathology.diagnomx.eu/ vs/5684057089135749

Keywords: BRAF, Mutation, Termination assay, Sequencing, Thyroid, Papillary carcinoma

\section{Introduction}

$B R A F$ is a serine/threonine kinase that functions as a part of the RAS/RAF/MEK /ERK/MAPK pathway, which is involved in the transduction of mitogenic signals from the cell membrane to the nucleus. A single hotspot mutation at nucleotide 1799 of $B R A F$ gene has been identified as the most common genetic event in papillary

\footnotetext{
*Correspondence: bijou@skku.edu; kkmkys@skku.edu

'Department of Pathology, Samsung Medical Center, Sungkyunkwan University School of Medicine, 50 Ilwon-dong, Gangnam-gu, Seoul 135-710, Korea

Full list of author information is available at the end of the article
}

thyroid carcinoma (PTC) with a prevalence of 29-83\% [1]. Recently, systematic review and meta-analyses on PTC showed that BRAF mutation is significantly associated with recurrence, lymph node metastasis, extrathyroidal extension and advanced tumor stages [2-4]. So far, detection of this mutation has been achieved by co-amplification at lower denaturation temperature (COLD)-PCR, allelespecific polymerase chain reaction (AS-PCR), highresolution melting curve (HRM) analysis, SNaPshot Assay, pyrosequencing and direct sequencing. Each technique has advantages and limitations with regard to cost, availability, and enrichment efficiency.

\section{Biomed Central}

(c) 2013 Kang et al.; licensee BioMed Central Ltd. This is an Open Access article distributed under the terms of the Creative Commons Attribution License (http://creativecommons.org/licenses/by/2.0), which permits unrestricted use, distribution, and reproduction in any medium, provided the original work is properly cited. 
Direct sequencing is widely accepted as the standard for the determination of mutations in formalin-fixed, paraffin-embedded (FFPE) tissue samples although this technique is time consuming, expensive [5,6] and the sensitivity is relatively low $[7,8]$. A key limitation of PCR-based methods in the detection of BRAF mutations is the inability to selectively amplify low percentages of variant alleles from a wild-type allele background [9]. In this study, we first applied shifted termination assay (STA) fragment analysis to detect the common hot-spot $B R A F$ mutation in 159 PTCs and compared the results to those of direct sequencing using DNAs from FFPE tissue samples consisting of 53 tumors less than $0.5 \mathrm{~cm}$ in size.

\section{Materials and methods}

\section{Patients and tumor samples}

One hundred and fifty nine PTCs were randomly retrieved from the surgical pathology files of Samsung Medical Center, Seoul, Korea between 2010 and 2011. The study was approved by the Institutional Review Board of the Samsung Medical Center (IRB \#2009-09010). The informed consent was obtained from the patient for genetic test and research. A pathologist (Ahn S) performed additional review of each case to confirm diagnosis and select the tumors. The patients included 27 men $(17 \%)$ and 132 women (83\%) with a mean age of 48 years (range, $17-76$ years). The mean tumor size was $0.76 \mathrm{~cm}$ (range, 0.1-6.5 cm).

\section{DNA extraction and BRAF mutant cell line}

Genomic DNA was extracted from two $4 \mu \mathrm{m}$ thick sections of FFPE tumor blocks under microscopy as previously described [10] using the QIAamp DNA Mini Kit (QIAGEN, Hilden, Ger.). The concentration and purity of the extracted DNA were determined by a ND-1000 spectrophotometer (NanoDrop Technologies, Inc. Wilmington, DE, USA). The extracted DNA was stocked at $4^{\circ} \mathrm{C}$ until use.

DNAs from SNU-790 cell lines were used as positive control and normal human genomic DNAs (Roche Applied Science, Penzberg, Ger.) were used as negative control. Serial dilutions of the positive cell line with normal human genomic DNAs to create final tumor DNA concentrations with $100 \%, 50 \%, 25 \%, 12.5 \%, 5 \%$ and $1 \%$ were used to compare the analytical limit of detection (LOD).

\section{Shifted Termination Assay (STA) fragment analysis}

Applied Biosystems ${ }^{\oplus} B R A F$ mutation analysis reagents assays were used for detection of three different $B R A F$ variants (V600E, V600A, and V600G) (Applied Biosystems, CA, USA). The manufacturer's protocol was followed for the amplification of DNA, clean-up of PCR products, and primer extension reactions. After primer extension, capillary electrophoresis and fragment analysis were performed. PCR reactions were performed in $30 \mu \mathrm{L}$ volumes using template DNA, BRAF PCR primers, and DNA amplification master mix. PCR was performed using a C1000 (Bio-Rad, CA, USA) and PCR cycling conditions were a 5 minute hold at $94^{\circ} \mathrm{C}$, followed by 35 cycles of $94^{\circ} \mathrm{C}$ for 30 seconds, $52^{\circ} \mathrm{C}$ for 45 seconds, $72^{\circ} \mathrm{C}$ for 45 seconds, and $72^{\circ} \mathrm{C}$ for $5 \mathrm{mi}$ nutes. After PCR, labeled PCR tubes were cleaned up, and $2 \mu \mathrm{L}$ of the labeled products were mixed with 9.5 $\mu \mathrm{L}$ of HiDi-formamide and $0.5 \mu \mathrm{L}$ of Genescan SD-130 size standard. The products were separated using a 40 minute run on an ABI Prism 3130 DNA sequencer with POP7 matrix and injection 14 seconds injection time. GeneMapper software, version 4.1 (Applied Biosystems) was used for analysis of the data.

\section{Polymerase chain reaction (PCR) and direct sequencing}

The mutational analyses of $B R A F$ exon 15 were performed by direct sequencing of PCR products amplified from genomic DNA, as previously described [10]. PCR was performed in a $20 \mu \mathrm{L}$ volume containing 100 ng of template DNA, 10x PCR buffer; $0.25 \mathrm{mM}$ dNTPs, 10 pmol primers, and $1.25 \mathrm{U}$ Taq DNA polymerases (iNtRON, Korea). Bi-directional sequencing was performed using the BigDye Terminator v1.1 kit (Applied Biosystems) on an ABI 3130 genetic analyzer (Applied Biosystems). Sequencher version 4.10.1 (Gene Codes Corporation, Ann Arbor, MI, USA) was used along with manual chromatogram reviews. The results were considered mutationpositive if a mutation was detected in both the forward and reverse DNA strands.

\section{Statistical analysis}

Statistical analyses were performed using SPSS statistical software version 19.0 (SPSS, Inc., Chicago, IL, USA). The level of agreement between genotyping findings by different methods was determined with kappa (к) statistics. Genotyping results were considered concordant in cases of sequence agreement between assays and discordant in cases where no genotype similarity was observed. A p value of $<0.05$ was considered statistically significant.

\section{Results}

In STA fragment analysis, BRAF mutation was detected in 119 (74.8\%) PTCs and all mutations were V600E. After serial dilutions of $B R A F$ mutant cell line, LOD of STA fragment analysis was $6 \%$. By direct sequencing, $B R A F$ V600E mutations were found in 118 (74.2\%) cases and LOD was $12.5 \%$. The correlation between STA-fragment analysis and direct sequencing was strong $(\mathrm{p}<0.00001)$ and a high level of agreement was 
Table 1 Comparisons of assay performance of direct sequencing versus STA fragment analysis and DPO-PCR

\begin{tabular}{lccc}
\hline & \multicolumn{2}{c}{ Direct sequencing } & Agreement \\
\cline { 2 - 4 } & V600E & Wild type & \\
\hline STAfragment analysis & 118 & 1 & K, 0.98(95\% Cl, 0.98 to 0.99) \\
V600E Mutant & 0 & 40 & \\
wild type & 0 & & \\
\hline
\end{tabular}

observed [K, 0.98; 95\% CI, (0.98 to 0.99)] (Table 1). Only one case showed discrepant result; a BRAF mutation detected by STA fragment analysis was not detected by direct sequencing. Pathologic review of this discrepant case showed extrathyroidal extension and lymph node metastasis in spite of its small size $(0.6 \mathrm{~cm})$ (Figure 1$)$.

The clinicopathological characteristics of patients with $B R A F$ V600E mutation detected by direct sequencing are described in Table 2. In PTCs with pT3/T4 stages, $B R A F$ mutation was observed in $83.8 \%$ of cases. In pT $1 /$ T2 carcinomas, BRAF mutation was detected in $65.9 \%$ and this difference was statistically significant $(\mathrm{p}=0.007)$. Moreover, BRAF mutation was more common in PTCs with extrathyroidal invasion than PTCs without extrathyroidal invasion $(84.7 \%$ versus $62.2 \%, \mathrm{p}=0.001)$. However, $B R A F$ mutation was not significantly associated with patients' age, tumor size and lymph node metastasis $(\mathrm{p}>0.05)$.

To estimate time and costs for each method, we estimated them from the preparative step to the final interpretation of results. As 3130 ABI sequencer in our laboratory is a 16-channel model, we calculated the sample size at 16. STA fragment analysis required 4 hours and 50 minutes while direct sequencing took 7 hours and 30 minutes. To run 16 samples, STA fragment analysis costs $34 \$$ and direct sequencing requires $25 \$$.

\section{Discussion}

In PTCs, BRAF mutation is an important prognostic marker. To detect $B R A F$ mutation, direct sequencing has been widely accepted as the gold standard. However, this technique requires rather expensive equipment, can be laborious and time consuming. To be applicable in many clinical laboratories with limited equipments, diverse testing methods are required to detect $B R A F \mathrm{mu}-$ tations. For this purpose, we first tested STA fragment analysis to detect BRAF V600 mutation in 159 PTCs obtained from FFPE tissue samples and found that STA fragment analysis is as sensitive as direct sequencing and can be easily applicable with lower costs and less running time. Moreover, BRAF mutation was associated with extrathyroidal extension and advanced tumor stage in PTCs.

$B R A F$ is the strongest activator in the downstream of MAP kinase signaling. In PTCs, the prevalence of $B R A F$ mutation has been variable among different studies and its association with clinicopathological features was controversial. Recently, systematic review and meta-analyses
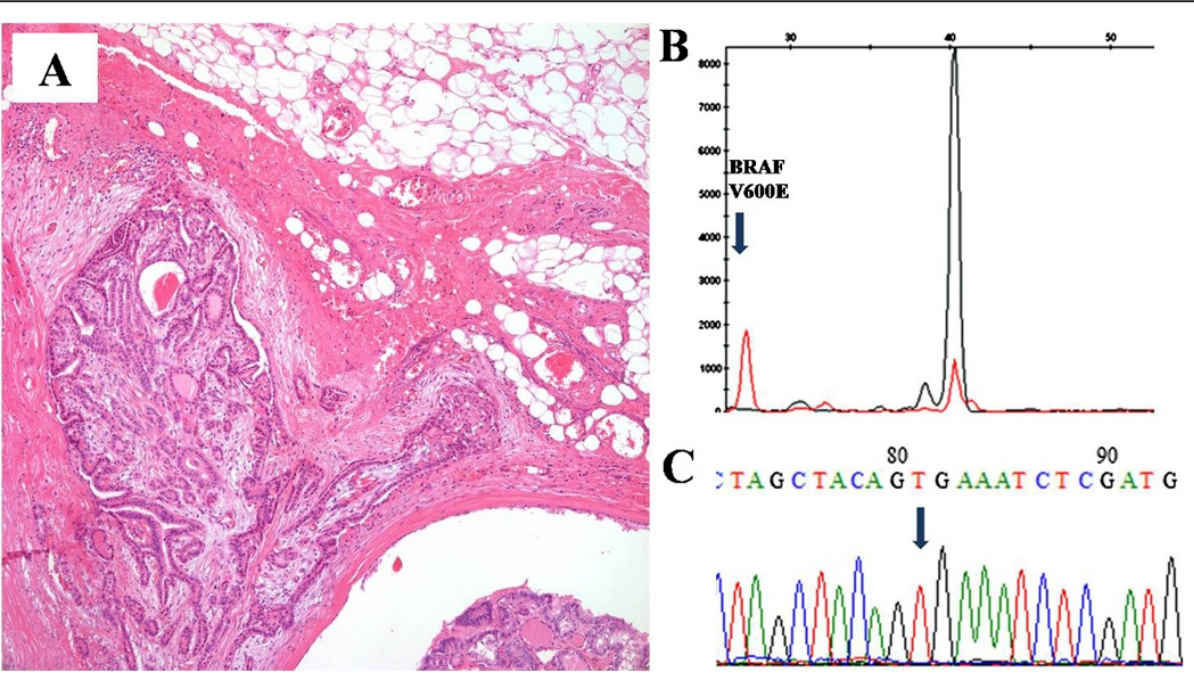

Figure 1 A papillary thyroid carcinoma with discrepant $B R A F$ mutation results in STA fragment analysis and direct sequencing.

(A) Pathology showing extrathyroidal extension. (B) BRAF mutation detected by STA fragment analysis. (C) Sequencing result showing wild-type for BRAF mutation. 
Table 2 Clinicopathologic characteristics in 159 patients with papillary thyroid carcinoma

\begin{tabular}{lccc}
\hline & \multicolumn{2}{c}{ BRAF V600E mutation } & P \\
\cline { 2 - 3 } Characteristic & Positive & Negative & \\
\hline Age $(y)$, Mean \pm SD & $47.70 \pm 10.69$ & $48.29 \pm 11.62$ & 0.602 \\
Gender & & & 0.422 \\
Male & 21 & 6 & \\
Female & 97 & 35 & \\
Tumor size $(\mathrm{cm})$, Mean \pm SD & & & 0.506 \\
$<0.5$ & 42 & 11 & \\
$0.5-1$ & 55 & 20 & \\
$>1$ & 21 & 10 & \\
T classification & & & $\mathbf{0 . 0 0 7}$ \\
T1/T2 & 56 & 29 & \\
T3/T4 & 62 & 12 & \\
Lymph node metastasis & & & \\
Yes & 43 & 15 & \\
No & 75 & 26 & \\
Extrathyroidal extension & & & \\
Yes & 72 & $\mathbf{0 . 0 0 1}$ \\
No & 46 & 28 & \\
\hline
\end{tabular}

on PTC showed that BRAF mutation is significantly associated with recurrence, lymph node metastasis, extrathyroidal extension and advanced tumor stages [2-4]. In medullary thyroid carcinoma, RET oncogene mutation correlates with a worse outcome [11]. In this study, although we failed to find the relationship between $B R A F$ mutation and lymph node metastasis, we confirmed that $B R A F$ mutation is closely associated with extrathyroidal extension and advanced tumor stage. In our previous study on $B R A F$ mutations using very highly sensitive dual-priming oligonucleotide-PCR and mutant enrichment with 3 '-modified oligonucleotide sequencing in 4,585 consecutive cases in fine needle aspiration cytology specimens, $B R A F$ mutation was not significantly associated with pT stage, extrathyroidal extension and lymph node metastasis [12]. In the present study, although the numbers of cases are small, we found that $B R A F$ mutation was significantly associated with extrathyroidal extension and advanced tumor stages using the FFPE PTC tissue samples and standard method to detect $B R A F$ mutations. These results are consistent with previous observations [2-4].

In order to be applicable in clinical laboratories, the diagnostic assay should address several issues related to the LOD, affordability, turnaround time and running costs. A variety of methods have been applied for $B R A F$ mutations. PCR-based screening methods such as SNaPshot assays, AS-PCR, COLD-PCR, Taqman ${ }^{\oplus}$ SNP assay, pyrosequencing and HRM analysis have been applied and the commonly used methods in pathology laboratories are summarized in Table 3 [13-18]. Although direct sequencing of PCR products is the gold standard for $B R A F$ mutation detection in routine diagnostics, it remains laborious, time consuming and requires rather expensive equipment [5,6]. In this study, we compared LOD, total operation time and costs for the detection of $B R A F$ mutation between STA fragment analysis and direct sequencing. STA fragment analysis cannot detect $B R A F$ mutations outside the targeted codon although direct sequencing can detect mutations located outside targeted codon. However, in PTCs, BRAF V600E is the most common hot spot mutation and was the only mutation found in 159 PTCs in this study. In our study, one PTC with small size $(0.6 \mathrm{~cm})$ and wild-type in direct sequencing turned out to harbor $B R A F$ V600E mutation by STA fragment analysis. The LOD using a $B R A F$ mutant cell line also showed higher sensitivity compared to direct sequencing. In cases with small carcinomas, a more sensitive assay is required to detect rare mutations. In this context, although the numbers of examined cases

Table 3 Summary of literature reviews on BRAF mutation analyses in recent publications

\begin{tabular}{llcccc}
\hline Journal (references) & Year & Organ & Tissue & No. of cases & Methods \\
\hline Present study & 2012 & Thyroid & FFPE and cell line & 159 & STA fragment analysis, direct sequencing \\
J Mod Diagn [19] & 2012 & Lung and colon & FFPE and cell line & 152 & HRM-sequencing and HRM-SNaPshot \\
PLOS One [20] & 2011 & Brain & FFPE & 97 & SNaPshot \\
Eur J Endocrinol [21] & 2011 & Thyroid & fresh tissues & 90 & Real-time PCR \\
PLOS One [8] & 2011 & Lung & Cytology and FFPE & 447 and 42 & Real-time PCR \\
J Mod Diagn [22] & 2011 & Colon & FFPE & 42 & Multiplex SNaPshot \\
Clin Chim Acta [9] & 2011 & Skin & FFPE & 45 & COLD-PCR \\
J Mod Diagn [14] & 2011 & Colon & FFPE & 125 & Real-time PCR \\
Hum Pathol [4] & 2010 & Thyroid & FFPE & 76 & RFLP \\
Genes Chromosomes Cancer & 2010 & Skin & FFPE & 116 & conventional PCR \\
\hline
\end{tabular}


are small, STA fragment analysis is a sensitive method to detect V600 BRAF mutation and needs shorter running time and lower costs compared to direct sequencing. In clinical laboratories performing MSI analyses by fluorescent PCR-based method using an ABI PRISM ${ }^{\circ}$ 3100 , STA fragment analysis can be used as an easily applicable, rapid and cost effective method to detect $B R A F$ V600E mutations in FFPE clinical samples.

\section{Abbreviations}

DPO-PCR: Dual-priming oligonucleotide-PCR.

\section{Competing interests}

The authors declare that they have no competing interests.

\section{Authors' contributions}

SYK, KM Kim and YL Oh designed the study and wrote the manuscript. SYK, SA, SML, JYJ, JYS, YL Oh and KMK acquired data. SYK and KMK managed the statistical analysis. All authors read and approved the final manuscript.

\section{Acknowledgements}

This work was supported by grant from the Korea Healthcare Technology R\&D project, Ministry for Health \& Welfare Affairs, Republic of Korea (A101130) and a grant from Samsung Biomedical Research Institute (\#SBRI-SP1B20112).

\section{Author details \\ 'Department of Pathology, Samsung Medical Center, Sungkyunkwan University School of Medicine, 50 llwon-dong, Gangnam-gu, Seoul 135-710, Korea. ${ }^{2}$ Department of Pathology, The University of Texas Health Science Center at San Antonio, San Antonio, Texas, USA. ${ }^{3}$ Department of Pathology, Kyungpook National University Hospital, Kyungpook National University School of Medicine, Daegu, Korea. ${ }^{4}$ Department of Pathology, KyungHee University Medical Center, KyungHee University School of Medicine, Seoul, Korea. ${ }^{5}$ Department of Genetic Engineering, Sungkyunkwan University, Suwon 440-746, Korea.}

Received: 7 February 2013 Accepted: 11 June 2013 Published: 24 July 2013

\section{References}

1. Trovisco V, Vieira De Castro I, Soares P, Maximo V, Silva P, Magalhaes J, Abrosimov A, Guiu XM, Sobrinho-Simoes M: BRAF mutations are associated with some histological types of papillary thyroid carcinoma. J Pathol 2004, 202:247-251.

2. Chakraborty A, Narkar A, Mukhopadhyaya R, Kane S, D'Cruz A, Rajan MG: BRAF V600E mutation in papillary thyroid carcinoma: significant association with node metastases and extra thyroidal invasion. Endocr Pathol 2012, 23:83-93.

3. Tufano RP, Teixeira GV, Bishop J, Carson KA, Xing M: BRAF mutation in papillary thyroid cancer and its value in tailoring initial treatment: a systematic review and meta-analysis. Medicine (Baltimore) 2012 91:274-286

4. Smith RA, Salajegheh A, Weinstein S, Nassiri M, Lam AK: Correlation between BRAF mutation and the clinicopathological parameters in papillary thyroid carcinoma with particular reference to follicular variant. Hum Pathol 2011, 42:500-506.

5. Didelot A, Le Corre D, Luscan A, Cazes A, Pallier K, Emile JF, Laurent-Puig P, Blons H: Competitive allele specific TaqMan PCR for KRAS, BRAF and EGFR mutation detection in clinical formalin fixed paraffin embedded samples. Exp Mol Pathol 2012, 92:275-280.

6. Farina Sarasqueta A, Moerland E, De Bruyne H, De Graaf H, Vrancken T, Van Lijnschoten G, Van den Brule AJ: SNaPshot and StripAssay as valuable alternatives to direct sequencing for KRAS mutation detection in colon cancer routine diagnostics. J Mol Diagn 2011, 13:199-205.

7. Kotoula V, Charalambous E, Biesmans B, Malousi A, Vrettou E, Fountzilas G, Karkavelas G: Targeted KRAS mutation assessment on patient tumor histologic material in real time diagnostics. PLoS One 2009, 4:e7746.
8. Querings $S$, Altmuller J, Ansen S, Zander T, Seidel D, Gabler F, Peifer M, Markert E, Stemshorn K, Timmermann B, Saal B, Klose S, Ernestus K, Scheffler M, Engel-Riedel W, Stoelben E, Brambilla E, Wolf J, Nurnberg P, Thomas RK: Benchmarking of mutation diagnostics in clinical lung cancer specimens. PLoS One 2011, 6:e19601.

9. Pinzani P. Santucci C, Mancini I, Simi L, Salvianti F, Pratesi N, Massi D, De Giorgi V, Pazzagli M, Orlando C: BRAFV600E detection in melanoma is highly improved by COLD-PCR. Clin Chim Acta 2011, 412:901-905.

10. Kim KM, Lee EJ, Ha S, Kang SY, Jang KT, Park CK, Kim JY, Kim YH, Chang DK, Odze RD: Molecular features of colorectal hyperplastic polyps and sessile serrated adenoma/polyps from Korea. Am J Surg Pathol 2011, $35: 1274-1286$

11. Gonzalez-Yebra B, Peralta R, Gonzalez AL, Ayala-Garcia MA, De Zarate ME, Salcedo M: Genetic alterations in a primary medullary thyroid carcinoma and its lymph node metastasis in a patient with 15 years follow-up. Diagn Pathol 2012, 7:63.

12. Lee ST, Kim SW, Ki CS, Jang JH, Shin JH, Oh YL, Kim JW, Chung JH: Clinical implication of highly sensitive detection of the BRAF V600E mutation in fine-needle aspirations of thyroid nodules: a comparative analysis of three molecular assays in 4585 consecutive cases in a BRAF V600E mutation-prevalent area. J Clin Endocrinol Metab 2012, 97:2299-2306.

13. Stadelmeyer $E$, Heitzer $E$, Wolf $P$, Dandachi N: COLD-HRM PCR versus conventional HRM PCR to detect the BRAF V600E mutation A real improvement? J Mol Diagn 2011, 13:243-244.

14. Lang AH, Drexel H, Geller-Rhomberg S, Stark N, Winder T, Geiger K, Muendlein A: Optimized allele-specific real-time PCR assays for the detection of common mutations in KRAS and BRAF. J Mol Diagn 2011, 13:23-28.

15. Li J, Wang L, Mamon H, Kulke MH, Berbeco R, Makrigiorgos GM: Replacing $P C R$ with COLD-PCR enriches variant DNA sequences and redefines the sensitivity of genetic testing. Nat Med 2008, 14:579-584

16. Verma S, Greaves WO, Ravandi F, Reddy N, Bueso-Ramos CE, O'Brien S, Thomas DA, Kantarjian H, Medeiros LJ, Luthra R, Patel KP: Rapid detection and quantitation of BRAF mutations in hairy cell leukemia using a sensitive pyrosequencing assay. Am J Clin Pathol 2012, 138:153-156.

17. Shen S, Qin D: Pyrosequencing data analysis software: a useful tool for EGFR, KRAS, and BRAF mutation analysis. Diagn Pathol 2012, 7:56.

18. Heideman DA, Lurkin I, Doeleman M, Smit EF, Verheul HM, Meijer GA, Snijders PJ, Thunnissen E, Zwarthoff EC: KRAS and BRAF Mutation Analysis in Routine Molecular Diagnostics: Comparison of Three Testing Methods on Formalin-Fixed, Paraffin-Embedded Tumor-Derived DNA. J Mol Diagn $2012,14 \cdot 247-255$

19. Dias-Santagata D, Lam Q, Vernovsky K, Vena N, Lennerz JK, Borger DR, Batchelor TT, Ligon KL, lafrate AJ, Ligon AH, Louis DN, Santagata S: BRAF V600E mutations are common in pleomorphic xanthoastrocytoma: diagnostic and therapeutic implications. PLoS One 2011, 6:17948.

20. Durante C, Tallini G, Puxeddu E, Sponziello M, Moretti S, Ligorio C, Cavaliere A, Rhoden KJ, Verrienti A, Maranghi M, Giacomelli L, Russo D, Filetti S: BRAF(V600E) mutation and expression of proangiogenic molecular markers in papillary thyroid carcinomas. Eur J Endocrinol 2011, 165:455-463.

21. Magnin S, Viel E, Baraquin A, Valmary-Degano S, Kantelip B, Pretet J Mougin C, Bigand M, Girardo B, Borg C, Ferrand C: A multiplex SNaPshot assay as a rapid method for detecting KRAS and BRAF mutations in advanced colorectal cancers. J Mol Diagn 2011, 13:485-492.

22. Conway C, Beswick S, Elliott F, Chang YM, Randerson-Moor J, Harland M, Affleck P, Marsden J, Sanders DS, Boon A, Knowles MA, Bishop DT, NewtonBishop JA: Deletion at chromosome arm 9p in relation to BRAF/NRAS mutations and prognostic significance for primary melanoma. Genes Chromosomes Cancer 2010, 49:425-438.

doi:10.1186/1746-1596-8-121

Cite this article as: Kang et al: Shifted termination assay (STA) fragment analysis to detect BRAF V600 mutations in papillary thyroid carcinomas. Diagnostic Pathology 2013 8:121. 